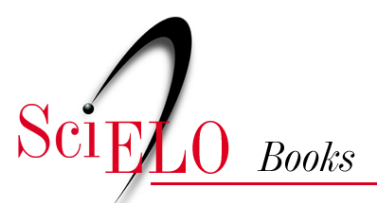

\title{
Considerações Finais
}

\author{
Juliana Gesuelli Meirelles
}

\section{SciELO Books / SciELO Livros / SciELO Libros}

MEIRELLES, J. G. Considerações Finais. In: Política e cultura no governo de Dom João VI: imprensa, teatros, academias e bibliotecas (1792-1821) [online]. São Bernardo do Campo, SP: Editora UFABC, 2017, pp. 431-440. ISBN 978-85-68576-87-8. https://doi.org/10.7476/9788568576878.0006.

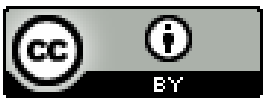

All the contents of this work, except where otherwise noted, is licensed under a Creative Commons Attribution 4.0 International license.

Todo o conteúdo deste trabalho, exceto quando houver ressalva, é publicado sob a licença Creative Commons Atribição 4.0.

Todo el contenido de esta obra, excepto donde se indique lo contrario, está bajo licencia de la licencia Creative Commons Reconocimento 4.0. 


\section{CONSIDERAÇÕES FINAIS}

Em 26 de abril de 1821 D. João VI e seu séquito retornavam ao Velho Mundo, depois de treze anos habitando o Brasil. A notícia da partida do maior representante da monarquia bragantina, no periódico da Corte, não escondia a aura de melancolia e tristeza. Chancelado nas palavras do gazeteiro Manoel Ferreira de Araújo Guimarães, na Gazeta do Rio de Janeiro, o discurso oficial tinha um tom saudosista, emblemático de um tempo de grandes mudanças, avanços e conquistas. ${ }^{1}$ Em 1808, como Príncipe Regente há dezesseis anos (1792-1808), D. João havia escolhido a sua possessão americana como residência para consolidar uma de suas mais delicadas missões: a salvaguarda da integridade política do Império Português, em meio à grave crise em que a Europa estava imersa devido às guerras napoleônicas. Sete anos depois da sua chegada ao Rio de Janeiro, o Regente elevava o Brasil a Reino Unido de Portugal e Algarves (1815). Também do lado americano do Atlântico, o monarca foi aclamado Rei do Império luso-brasileiro (1818), assim como, três anos depois (1821), aceitou as exigências políticas interatlânticas da sociedade joanina que clamava pelas Cortes reivindicando o constitucionalismo. Enfim, se D. João chegou ao Brasil ainda Príncipe Regente absoluto, retornava à Europa Rei constitucional.

1 GRJ. 1821. № 34. 
As transformações sociopolíticas e culturais foram profundas. Para compreendê-las, procuramos esclarecer as linhas mestras da política joanina ao longo de sua governança (17921821) no mundo luso-brasileiro, tendo em vista a importância da estruturação e vigência de quatro locus de cultura do Império Português: a imprensa interatlântica, os reais teatros, a Real Academia Militar e as reais bibliotecas. Sob as diretrizes do iluminismo luso-brasileiro, a investigação das especificidades de cada um desses espaços de ampla interlocução social, nos apontou as principais bases da política cultural de D. João VI, sobretudo em relação à produção, troca de saberes e circulação de informações nos campos da arte e da ciência entre o Velho Continente e o Novo Mundo.

Através da perspectiva interatlântica, vislumbramos vieses fundamentais da política cultural da monarquia portuguesa, entre os anos de 1792 a 1821. A política cultural joanina esteve intrinsecamente associada à atuação política mais ampla da Coroa tanto na relação de D. João com seus principais homens de Estado, incluindo-se os Intendentes Gerais da Polícia, quanto com a formação intelectual de seus súditos ilustrados nos diversos espaços de cultura e educação nas cidades politicamente fundamentais na sustentação do Império Português, alicerçadas em Lisboa e Rio de Janeiro, com destaque diplomático também para Londres. A despeito das divergências políticas, a Coroa britânica foi a principal aliada da Coroa portuguesa na Europa neste período. Ainda na capital inglesa, eram produzidos os principais jornais do período, O Correio Braziliense e O Investigador Portuguez em Inglaterra.

Ao investigarmos o complexo universo da imprensa como locus de produção de saber, adentramos em uma situação deveras particularizada. Seja através da liberdade de imprensa que 
vigorava em Londres, seja em meio ao sistema de censura vigente no Império Português, a produção da palavra impressa veiculada nos jornais luso-brasileiros esteve intimamente associada às relações políticas e diplomáticas da Coroa portuguesa com as nações europeias, mormente França e Inglaterra. Ademais, as discussões públicas de temas caros à formação da opinião pública mostraram como a condução da pena desses homens de letras tinha uma missão comum: o debate acerca dos melhores caminhos para que a sociedade civil luso-brasileira fosse instruída e educada dentro da concepção de progresso da época, cujo sentido estava intrínseco ao adiantamento em proveito das artes e ciências, dois campos do saber ainda tão interdependentes e vinculados à força do pragmatismo pedagógico.

Já a complexidade do universo artístico apreendia outras dimensões simbólicas. Do nascimento desses espaços de cultura, como o Real Teatro de São Carlos (Lisboa) ou os Reais Teatros de São João (Porto e Rio de Janeiro), notamos a conexão entre os novos tempos pós Revolução Francesa e a emergência política e inserção das novas classes sociais, como a burguesia portuguesa, no Reino, e os negociantes de grosso trato e a nobreza lusitana, no Rio de Janeiro. Neste sentido, para a sociedade de corte luso-brasileira, o teatro foi um espaço importante de sociabilidade em que era possível polir as maneiras à semelhança das nações mais cultas da Europa, mas também delinear novas relações sociopolíticas que garantissem, no futuro, voos mais altos nos quesitos de visibilidade pública (sobretudo para a realeza) e riqueza. Neste sentido, o apoio financeiro a este empreendimento tornava-se, pouco a pouco, uma moeda de peso nas relações políticas entre a monarquia e seus súditos ilustrados. Para a Coroa, a construção e manutenção de uma casa artística de tamanha magnitude simbolizava o ápice da civilização dos costumes: um locus onde 
a realeza poderia celebrar as suas glórias políticas; um espaço de pedagogia política onde se educava os súditos através da exaltação dos valores morais mais caros ao Antigo Regime sem, com isso, abrir mão do refinamento do gosto através da valorização da alta cultura europeia.

Com as Reais Academias Militares a Coroa portuguesa objetivava metas ainda mais ousadas. Para além da educação moral dos súditos, calcada no respeito à hierarquia militar, primava-se pela formação intelectual institucionalizada desses sujeitos. Ao valorizar o estudo em diversos níveis - das primeiras letras à produção e apreensão de um conhecimento científico de ponta -, a Coroa buscava garantir a segurança territorial do Império Português em tempos de paz ou em tempos de guerra. Assim, com a alta profissionalização do exército real, o governo joanino também almejava a formação de um amplo contingente de mão de obra civil especializada: os engenheiros, que cuidariam das obras de infraestrutura nos dois lados do Atlântico. No Brasil, especificamente, o espaço também teve um viés simbólico muito forte: a estruturação e defesa deste amplo território apagava a mácula da humilhação política vivida pela Coroa Portuguesa ao transladar a capital do Império para a América, às vésperas da invasão de Napoleão Bonaparte a Lisboa. Enfim, se as Reais Academias Militares visavam, no plano ideal, provar a grandeza e solidez do Império, no plano real, enfrentaram grandes obstáculos e dificuldades: para além dos problemas infraestruturais - com a carência de material pedagógico e corpo docente e discente - a Real Academia Militar era um projeto exclusivo de d. Rodrigo de Sousa Coutinho. Com a sua morte, portanto, as objetivações de seus ideais ficaram em segundo plano para os ministros que o sucederam. A despeito disso, a exaltação do discurso de valorização do progresso através do conhecimento científico foi uma tônica 
imprescindível que extrapolou os muros da instituição e constituiu uma característica típica da figura do militar no período joanino. Ademais, foi também das salas da Real Academia Militar que se iniciou a formação dos quadros políticos que comporiam a administração estatal ao longo da primeira metade do século XIX.

A constituição das Bibliotecas Reais foi um projeto ambicioso da Coroa portuguesa desde D. João V (1706-1750). Se o riquíssimo acervo da Biblioteca Real ficou entre os escombros do terremoto de 1755, os reinados de D. José I, Da Maria I e D. João VI tratariam de manter uma sistemática política de recuperação do espaço (com a formação de novos acervos) através da constituição de três novos locus: a Real Biblioteca d'Ajuda (1756), a Real Biblioteca Pública da Corte (1794) e a Real Biblioteca do Rio de Janeiro (1810). O árduo esforço governamental para a consolidação desses lugares de cultura no Império Português é intrínseco à força simbólica de uma Biblioteca Régia na Idade Moderna: estas eram o lugar da memória da monarquia, representavam a superioridade intelectual e independência política do Império. E por essas razões absolutamente centrais para os reis absolutos, D. João não mediu esforços para o sucesso do processo de transladação da Biblioteca Real para a nova capital imperial, o Rio de Janeiro.

Desta forma, a constante política de aquisição e preservação de novas obras (fossem elas raras ou não) também colocava em cena a figura do bibliotecário: um súdito de fundamental importância escolhido por rígidos critérios de relevância. Para além da ampla formação intelectual geralmente vinculada à Universidade de Coimbra, este funcionário régio deveria ser um súdito fiel e leal à monarquia. Os bibliotecários eram homens que, entre muitas outras funções, pensavam o processo de leitura que interessava à Coroa veicular. Em outras palavras, tinham que ser 
bons leitores da realidade política do Império Português. ${ }^{2} \mathrm{~A}$ importância da Biblioteca Real foi de tamanha grandeza simbólica que, em 1825, o espaço entrou como um dos principais objetos intelectuais de negociação no processo de reconhecimento da Independência do Brasil. A consolidação desse difícil processo de separação política do Brasil custaria a D. Pedro I uma pesada indenização. Na Conta dos objetos que Portugal teria direito a reclamar ao Brasil, D. João VI cobrou do filho 800 mil contos de réis pelo acervo da Real Biblioteca que ficara no Rio de Janeiro. ${ }^{3}$ Com os devidos acertos financeiros, abria-se uma nova página na história do recente Império do Brasil sob a coroa de D. Pedro I.

Neste sentido, entrevemos pontos em comum entre os quatro locus de saber estudados nesta pesquisa. Todos visavam celebrar as glórias políticas da monarquia luso-brasileira com objetivos pedagógicos muito circunscritos: agir em prol da formação intelectual dos súditos através do ideal ilustrado intrinsecamente associado à educação. Porém, assim como os filósofos da Europa do Norte, também no Império Português o processo de formação dos súditos era perpassado por uma concepção de educação elitista e excludente. Isto é, adentrar no mundo do conhecimento era mérito para poucos.

Com isso, a política cultural da Dinastia de Bragança sob a cabeça de D. João VI visou a engrandecer-se simbolizando a sua força política através da constituição e engendramento de espaços de cultura nos dois lados do Atlântico. Em relação ao Brasil, a formação de tais locus não foi pensada única e exclusivamente para o deleite da Coroa, mas, antes, para preservar as representações

\footnotetext{
2 Sobre a importância dos homens de talento no período joanino, ver ALGRANTI, Leila Mezan. Livros de Devoção... Op. Cit., (cap. 7, p. 223-251).

3 SCHWARCZ, Lilia M., AZEVEDO, Paulo César de; COSTA, Ângela Márquez da, A longa viagem ... Op. Cit., p. 395.
} 
políticas da monarquia luso-brasileira. Os espaços iluminados vigentes na outra capital deveriam fazer parte da vida da corte, a partir de 1808. Por esse prisma, o que tem no Reino, necessariamente deve existir também na nova Corte, já que a residência do monarca tem que ser digna de sua persona. Cada uma dessas instituições compõe as imagens e símbolos do poder real, sendo diferentes expressões de uma mesma questão: a manutenção da integridade imperial pelo viés da formação pedagógica de bons súditos ilustrados.

Essa obra, portanto, buscou evidenciar a complexidade das relações sociopolíticas e culturais do Império Português em meio à grave crise política na Europa através da compreensão das ações governamentais para quatro locus de cultura de naturezas diferenciadas. O estudo desses espaços por uma perspectiva transatlântica foi crucial para delinearmos as dimensões da política cultural joanina que, em última análise, esteve voltada para a superação da crise política e a salvaguarda da integridade imperial luso-brasileira. Neste contexto, a consolidação de um novo Império com sede no Brasil era parte fundamental desse projeto, sendo imprescindível a busca pelo equilíbrio político nas (tensas) relações diplomáticas de Portugal com o Velho Mundo. Neste processo, a capitalidade do Rio de Janeiro como centro do Império, assim como a manutenção desse difícil diálogo político e diplomático ao longo de todo o período com a Europa, ganhou novas dimensões e tonalidades políticas, também tecidas dentro desses quatro locus de cultura. Cada um desses espaços de saber contou com o trabalho de muitos funcionários régios de diversos perfis intelectuais: dos homens de Estado aos homens de letras e ciência, D. João VI os escolhia através de um rígido critério de relevância. Porém, para além de suas diferenças, todos foram nomeados para seus respectivos cargos por serem, antes, súditos 
leais à monarquia. Isto é, para manter a Coroa sob sua cabeça com o devido respeito das demais nações europeias, D. João VI considerou vital a formação moral e intelectual de seus súditos ilustrados.

A despeito das especificidades culturais de cada um desses locus de saber, a governança joanina foi marcada sobremaneira por uma política cultural vinculada à busca da autonomia intelectual do Império Português que, em última instância, contribuiu profundamente para a consolidação de um novo ambiente cultural nos dois lados do oceano, com um maior grau de novidade no Rio de Janeiro. Dessa forma, ao apoiar institucionalmente grandes e diferentes projetos culturais com inspirações em suas respectivas congêneres lusitanas (gazetas e jornais, teatros, livros, bibliotecas, academias...), a Coroa portuguesa incentivava novas leituras da realidade entre muitos sujeitos históricos que viviam o cotidiano desse Império, incluindo aí também os escravos. Estes, mesmo marginalizados deste processo, vivenciaram pelas ruas da nova capital as novas reflexões sobre a política no espaço público sabendo esquadrinhar - com seus gritos e vozes públicas -, uma importante atuação política no espaço urbano, um domínio em que muitas vezes se sentiam senhores. Essas mudanças produziam consigo um constante jogo de apropriações de sentidos. ${ }^{4}$ Neste processo, o governo joanino, mesmo mantendo um amplo sistema de censura, também propiciou o florescimento de um novo espaço público de tonalidades liberais onde vigorou a crítica ao status quo. Como havia apregoado Immanuel Kant, em 1784, o Homem era culpado pela sua menoridade e, para transcendê-la, era imprescindível que este fizesse o uso público da razão. Eis o caminho a ser trilhado na senda do

\footnotetext{
${ }^{4}$ MOREL, Marco. As transformações... Op. Cit., p. 230.
} 
esclarecimento. ${ }^{5}$ Com as devidas ressalvas e limitações próprias ao iluminismo luso-brasileiro, a sociedade joanina apreendia algumas nuanças da lição do filósofo.

No raiar d'Oitocentos, a sociedade joanina nos dois lados do Atlântico emergia com uma força política inimaginável antes da Revolução Francesa: clamava pela monarquia constitucional, exigia representatividade nas Cortes, saía às ruas de forma coletiva (política e militarmente) organizada para discutir no espaço público seus desejos coletivos e direitos políticos. Propunha a liberdade de expressão com irrestrita liberdade de imprensa, fazendo desta uma importante arena de debates. Lia livros clássicos e, nas brechas da censura, tinha sob as mãos jornais e obras proibidas. Escrevia novas obras. Enfim, ousava recriar as suas identidades culturais criticamente, já que ao longo de pouco mais de trinta anos (1789-1821), apreendia o verdadeiro sentido da crítica intrínseco à morte do rei e à emergência do cidadão em um novo espaço público liberal onde todos seriam julgados igualmente perante a lei. ${ }^{6}$ Todas essas transformações também moldaram a persona D. João VI. De Príncipe Regente a Rei constunstitucional, D. João foi um monarca que viveu em um momento histórico de grandes turbulências políticas. Força e fragilidade eram as tônicas do seu tempo, do seu espaço e, quiçá, da sua personalidade. Um rei que consultava e parecia se orientar pelas opiniões, no geral contrastantes, de seus súditos ilustrados, quer sejam ministros ou escritores. Um rei que negociava mercês com seus súditos que de alguma forma o auxiliavam nas múltiplas tarefas da governança. Um rei que também se movimentava pela pressão da sociedade, visando sobretudo a garantir a coesão e integridade do todo, em

\footnotetext{
${ }^{5}$ KANT, Immanuel. Resposta à pergunta: ... Op. Cit., p. 104.

${ }^{6}$ KOSELLECK, Reinart. Crítica e Crise. Op. Cit., p. 103-104.
} 
outras palavras, a conservação do Império; tomou a iniciativa de propor e administrar instituições que atendessem seus interesses particulares, mas também as expectativas desta sociedade. Enfim, um rei que soube articular magnamente as chaves da diplomacia, pois estava situado entre a preservação do poder para a dinastia, as reivindicações conflitivas da sociedade e a competição internacional. ${ }^{7}$

Neste contexto, com a formação e vigência de todos esses novos espaços de cultura e saber, a nova capital do Império (Rio de Janeiro) começava a igualar-se em muitos sentidos à antiga sede do poder (Lisboa). Esse processo histórico evidenciou uma questão central: onde o Rei se encontrasse, os símbolos e expressões do seu poder estariam presentes, ratificando a sua força e superioridade dentro de uma visão ilustrada de mundo.

Em 1821, treze anos depois de sua chegada ao Brasil, a Coroa portuguesa voltava para o Velho Mundo. Se, porém, a realeza retornava sob os ventos liberais que elegiam um novo modelo político - o constitucionalismo -, fazia-o de forma muito habilidosa: independentemente das transformações políticas interatlânticas, a monarquia lusitana conseguiu sobreviver e se fortalecer ao longo do tempo, sem se curvar aos desígnios políticos e militares da França Napoleônica. Poucos monarcas alcançaram tal façanha. D. João VI foi um deles.

\footnotetext{
${ }^{7}$ Nesta reflexão, agradeço à professora Izabel Marson pelo diálogo profícuo acerca da persona de D. João VI.
} 